\title{
Menakar Direct Marketing dan Kepercayaan Pelanggan \\ Dalam Pembelian Paket Umrah
}

\author{
Adi Suparwo (1) \\ Mutiara Tristyantie (2) \\ Universitas Adhirajasa Reswara Sanjaya Bandung ${ }^{(1)(2)}$ \\ adi.suparwo@ars.ac.id ${ }^{(1)}$ \\ mutiaratristyantie01@gmail.com ${ }^{(2)}$
}

\begin{abstract}
This research aims to examine the implications of direct marketing and customer trust in the decision to purchase Umrah package at PT. Sanabil Madinah Barakah Bandung. This is supported by the rapid growth of tour and travel Umrah in some areas because of the needs of people who are mainly Muslims. The method used in this study is a verifiable, descriptive verificative using multiple linear regression where the free variables in this research are direct marketing and the trust of the customers and their current variables are purchase decisions. The sample techniques used in this research use nonprobability sampling techniques, namely purposive sampling techniques with samples obtained is a total of 92 respondents from a population of 1135 people. Simultaneous research resulted in the fact that direct marketing and customer trust jointly implicates the decision to purchase Umrah package at PT. Sanabil Madinah Barakah Bandung. This research shows that companies need to improve their direct marketing and customer trust in order to increase consumer buying decisions. Referring to this research, obtained by another invention of the variable that implicates the purchase decision seen from the greater coefficient of determinant is the trust of the customer, the better the company's control over employee service, facilities provided, and the guarantee of security to the customer, so it can also affect the customer's trust condition to the company that can ultimately increase the purchasing decision of the company.
\end{abstract}

Keywords: Purchase Decision; Direct Marketing; Customer Trust 
Penelitian ini bertujuan mengkaji implikasi direct marketing dan kepercayaan pelanggan terhadap keputusan pembelian paket umrah pada PT. Sanabil Madinah Barakah Bandung. Hal ini didukung dengan pesatnya pertumbuhan usaha tour and travel umrah dibeberapa daerah karena kebutuhan masyarakat yang terutama umat muslim. Metode yang digunakan dalam penelitian ini ialah kuantitatif deskriptif verifikatif menggunakan regresi linier berganda dimana variabel bebas pada penelitian ini ialah direct marketing dan kepercayaan pelanggan dan variabel terikatnya ialah keputusan pembelian. Teknik sampel yang digunakan dalam penelitian ini menggunkan teknik nonprobability sampling yaitu Teknik purposive sampling dengan sampel yang didapat ialah bejumlah 92 responden dari jumlah populasi sebanyak 1135 orang. Penelitian yang dilakukan secara simultan menghasilkan bahwa direct marketing dan kepercayaan pelanggan secara bersama-sama berimplikasi terhadap keputusan pembelian paket umrah pada PT. Sanabil Madinah Barakah Bandung. Penelitian ini menunjukan bahwa perusahaan perlu meningkatkan direct marketing dan kepercayaan pelanggan agar dapat meningkatkan keputusan pembelian konsumen. Mengacu pada penelitian ini, didapatkan penemuan lain yaitu variabel yang berimplikasi terhadap keputusan pembelian dilihat dari koefisien determinan parsial yang lebih besar adalah kepercayaan pelanggan, maka semakin baik pengendalian perusahaan terhadap pelayanan karyawan, fasilitas yang diberikan, dan jaminan keamanan terhadap pelanggan, maka hal tersebut dapat berpengaruh baik pula kepada kondisi kepercayaan pelanggan terhadap perusahaan yang pada akhirnya dapat meningkatkan keputusan pembelian pada perusahaan tersebut.

Kata Kunci : keputusan pembelian; direct marketing; kepercayaan pelanggan 


\section{PENDAHULUAN}

Perkembangan perusahaan tour \& travel umrah dan juga haji merupakan daya saing tersendiri dalam penyelenggaraannya. Masing-masing perusahaan mempunyai strategi pemasaran dalam memikat konsumen melalui strategi atau bagaimana pengolahan manajemen perusahaan tersebut untuk menghadapi persaingan yang ketat. Efektifitas dan efisiensi dalam pendayagunaan sumber daya perlu diperhatikan agar perusahaan dapat tumbuh dan berkembang. Suatu keberhasilan akan dicapai oleh perusahaan apabila perusahaan tersebut memiliki strategi yang jitu dan andal serta pemasarannya dapat diterapkan dengan tepat. Dalam menjalankan sebuah bisnis hal yang paling penting dilakukan adalah pemasaran. Pemasaran yang baik harus dapat memenuhi kebutuhan dan keinginan pelanggan sehingga akan mendapatkan keuntungan bagi perusahaan (Rodriguez et al., 2014).

Banyak faktor yang dapat mempengaruhi keputusan pembelian konsumen, yaitu promosi produk dan layanan yang diberikan perusahaan, kualitas pelayanan, harga, dan rekomendasi dari teman dan kerabat (Purnama, 2016). Promosi bukan hanya memperkenalkan kelebihan dari sebuah produk atau jasa juga menariknya harga yang ditawarkan serta membuatnya lebih terjangkau, melainkan promosi dilakukan agar komunikasi dengan konsumen, memperkenalkan serta membujuk pelanggan memutuskan menggunakan produk atau jasa yang perusahaan promosikan kepada konsumen tersebut. Menurut (Saladin, 2003) dalam buku Manajemen Pemasaran: "Promosi merupakan sebuah alat informasi antara penjual dan pembeli yang tujuannya adalah untuk mengamati tingkah laku dan mengubah sikap pembeli, yang pada awalnya belum mengetahui menjadi mengetahui sehingga membeli dan menjadi pembeli tetap yang mengingat produk tersebut".

Berdasarkan hal tersebut, PT. Sanabil Madinah Barakah atau Sanabil Tour \& Travel melakukan upaya promosi untuk meningkatkan tingkat penjualan perusahaan melalui Face to face selling, Telemarketing dan Online Marketing yang ketiganya terdapat pada program Direct Marketing. Menurut (Armstrong et al., 2014) dalam bukunya Principles of Marketing : "Pemasaran langsung adalah salah satu bentuk hubungan langsung, anda bisa mendapatkan respon langsung dari keduanya dan menjalin hubungan yang baik dengan pelanggan”. Saat melakukan tahap direct marketing perusahaan diwajibkan untuk menggunakan komponenkomponen penting yang termasuk kedalam direct marketing tersebut. Menurut (Kotler \& Keller, 2016) : "Surat pelanggan, email, fax, atau bahkan internet mrupakan alat komunikasi langsung yang meminta tanggapan dan melakukan percakapan dengan konsumen tertentu”. Berikut ini adalah data jamaah umrah PT. Sanabil Madinah Barakah Bandung mulai tahun 2017 hingga tahun 2019. 
Tabel 1

Jamaah Umrah Tahun 2017-2019 PT. Sanabil Madinah Barakah Bandung

\begin{tabular}{|c|c|c|c|}
\hline No & Tahun & L & P \\
\hline 1 & 2017 & 92 & 91 \\
\hline 2 & 2018 & 296 & 345 \\
\hline 3 & 2019 & 136 & 176 \\
\hline \multicolumn{2}{|c|}{ Jumlah } & 524 & 612 \\
\hline & Total Jamaah & \multicolumn{2}{|c|}{1136} \\
\hline
\end{tabular}

Sumber: Data Primer Manifest PT. Sanabil Madinah Barakah.

Dari tabel 1 tersebut dapat disimpulkan bahwa jumlah jamaah pada tahun 2017-2019 mengalami fluktuasi. Dapat dilihat bahwa jumlah jamaah pada tahun 2016 ialah 183 jamaah dan meningkat pada tahun 2018 yaitu 641 jamaah lalu menurun kembali ditahun 2019 dengan jumlah 312 jamaah. Penurunan tersebut dapat dikarenakan kurangnya informasi dari pihak PT. Sanabil Madinah Barakah kepada masyarakat, sehingga masyarakat kurang mengetahui PT. Sanabil Madinah Barakah. Selain dari direct marketing, keputusan pembelian juga dapat meningkat apabila adanya kepercayaan dari pelanggan yang dibangun oleh perusahaan tersebut. Kepercayaan pelanggan pada perusahaan merupakan asset perusahaan itu sendiri. Kepercayaan ialah suatu alat ukur konsumen yang dipergunakan untuk mengevaluasi produk yang diberikan produsen kepada konsumen (Siow, 2013). Menurut (Mowen \& Minor, 2002) kepercayaan pelanggan ialah apapun ilmu yang dimiliki pelanggan, dan apapun hasil akhir yang didapat oleh pelanggan tentang tujuan, atribut, dan manfaatnya. Pendapat (Barnes James, 2003) kepercayaan ialah keyakinan bahwa seseorang akan menjumpai apa yang mereka butuhkan dalam diri seorang mitra dagang.

Tabel 2

Data PT.Sanabil Madinah Barakah Terdaftar Dalam SIMPU Kemenag

\begin{tabular}{|c|c|}
\hline Nama & : PT. SANABIL MADINAH BARAKAH \\
\hline STATUS DAFTAR HITAM & TEMK \\
\hline Nomer SK & : NOMCR 934 TA-HUN 2017 \\
\hline Tanggal 5K & :03-10-2017 \\
\hline Name Direstur & : FAN USTAM \\
\hline Alamat kantor & $\begin{array}{l}\text { :L BRAGGA NO } 7 \text { KEL GRAGA KEC. SUMUR BANOUNG KOTA BANDUNG JAWA BRRAT TELP +6222 } 4242020 \text { FAX } \\
0224268565 \text { EMAIL S SANABILTOURGYHOOCOM }\end{array}$ \\
\hline Akreditasi & $: 3$ \\
\hline Tol Akrecitasi & $: 20-07-2017$ \\
\hline
\end{tabular}

Sumber; Simpu.Kemenag.go.id. 
Dari Tabel 2 diketahui bahwa Sanabil Tour \& Travel telah terdaftar di SIMPU Kementrian Agama. Namun data tersebut belum dapat membangun kepercayaan pelanggan terhadap Sanabil Tour \& Travel. Sehingga perusahaan harus berupaya untuk membangun kepercayaan tersebut kepada konsumen agar konsumen tertarik kepada Sanabil Tour \& Travel yang dapat meningkatkan keputusan pembelian tiket Umrah sehingga perusahaan dapat terus berjalan dan mendapatkan keuntungan yang lebih. Berdasarkan uraian diatas peneliti tertarik untuk meniliti seberapa besar implikasi direct marketing dan kepercayaan pelanggan terhadap keputusan pembelian tiket umrah pada perusahaan tour and travel PT. Sanabil Madinah Barakah.

\section{Direct Marketing}

Menurut (Tjiptono, 2008) direct marketing merupakan alat pemasaran yang sifatnya saling berhubungan, yang menggunakan salah satu atau bahkan macam-macam media advertising yang dapat menghasilkan tanggapan yang terukur dan juga disembarang tempat. Pendapat (Bennett, 2010) direct marketing ialah salah satu elemen paling utama dalam pemasaran. (Armstrong et al., 2014) mengemukakan "membuat hubungan baik antara penjual dan pembeli dengan kontak langsung serta cermat yang ditujukan ke perseorangan agar mendapatkan respon diantara kedua pihak meupakan pemasaran langsung". Dari definisidefinisi sebelumnya dapat diambil kesimpulan bahwa direct marketing ialah suatu strategi bisnis yang bertujuan untuk mendapatkan respon dari konsumen secara langsung untuk mendapatkan tanggapan yang terukur.

Menurut (Armstrong et al., 2014) indikator direct marketing, yaitu :

1. Face to face selling

Menurut (Basu Swastha, 2007) face to face selling adalah pengetahuan dan seni mempengaruhi yang dilakukan oleh penjual untuk membujuk orang lain menggunakan dan membeli barang atau jasa yang disediakan.

\section{Telemarketing}

Pendapat (Philip Kotler \& Keller, 2007) telemarketing adalah penggunaan jaringan telepon dan call center untuk menarik pelanggan ptensila dan menyediakan produk kepada konsumen. Telemarketing dapat diatur pada waktu yang tepat untuk menarik calon pembeli, dan materi pemasaran langsung memiliki jumlah pembaca yang tinggi karen adapat disampaikan kepada pelanggan potensial. 


\section{Online marketing.}

Menurut (Kotler, 2008) online marketing adalah sebuah bentuk pemasaran yang pada basisnya merupakan situs publik, berpengaruh besar terhadap jaringan komputer yang tipenya berbeda. Serta jaringan tersebut berasal dari beragam negara di seluruh bagian dunia. Terhubung satu dengan lainnya pada sebuah wadah informasi yang sangat besar. Lebih dalam lagi Kotler dan Amstrong berpendapat bahwa online marketing adalah bagian dari e-Marketing dan e-Business. Sehingga sangat penting memanfaatkan media internet dalam rangka membangun hubungan dengan pelanggan.

\section{Kepercayaan Pelanggan}

Menurut (Barnes James, 2003) kepecayaan ialah seseorang percaya bahwa dia akan menemukan semua keinginannya di mitra pertukarannya. Keyakinan ini menyangkut kesiapan seseorang untuk berekspresi dengan cara tertentu, karena keyakinan ini adalah bahwa mitra akan memberikan apa yang diinginkannya, dan orang pada umumnya mengharapkan perkataan, perbuatan, janji atau pernyataan seeorang dapat dipercaya.

Pendapat (Mayer et al., 1995) menjelaskan mengenai tiga unsur yang dapat membangun kepercayaan, yaitu :

1. Kemampuan (Ability)

Dalam mempengaruhi dan menguasasi suatu wilayah, diperlukan suatu kemampuan yang didalamnya terdapat kompetensi dan ciri khas penjual. Kemampuan tersebut diantaranya adalah penjual mampu menyediakan, melayani, dan membuat aman ketika melakukan transaksi sehingga konsumen mendapatkan jaminan keamanan dan merasa puas.

2. Kebaikan hati (Benevolence)

Pemberian kepuasan yang berdasar dari kemauan penjual dengan saling menguntungkan antara kedua belah pihak merupakan suatu kebaikan hati. Dalam berbisnis tidak hanya semata untuk menghasilkan keuntungan, melainkan ada perasaan ingin mewujudkan kepuasan konsumen dengan memberikan perhatian yang lebih.

3. Integritas (Integrity)

Ketika menjalankan bisnisnya, penjual memiliki sikap atau kebiasaan yang merupakan suatu integritas. Contoh dari sikap penjual adalah pemberian informasi yang fakta atau tidak kepada konsumen dan kepercayaan terhadap kualitas produk. 


\section{Keputusan Pembelian}

Produsen mengharapkan perushaan membuat keputusan pembelian. Keputusan pembelian untuk membeli suatu produk atau jasa adalah karena rangsangan emosi sendiri ataupun pengaruh orang lain (Suparwo et al., 2017; Wahyuni dan Darma, 2019). Pendapat (Schiffman \& Kanuk, 2004) keputusan pembelian adalah memilih dua atau lebih alternatif pilihan keputusan pembelian, yang artinya seseorang dapat mengambil keputusan dan harus ada beberapa alternatif pilihan.

Pendapat (Philip Kotler \& Armstrong, 2012) indikator keputusan pembelian yaitu:

1. Pilihan Produk

Pelanggan dapat mempergunakan uangnya untuk pembelian produk atau tujuan lain dalam kehidupannya. Perusahaan perlu berusaha menarik perhatian orang banyak untuk berminat membeli produk dan memikirkan berbagai macam pilihan, yaitu:
a. Keunggulan Produk
b. Manfaat Produk
c. Pemilihan Produk

\section{Pilihan Merk}

Pelanggan perlu mengambil keputusan merk mana yang akan ia beli. Setiap merk mempunyai ciri khas tersendiri. Karena hal tersebut, perusahaan perlu mengetahui bagaimana konsumen menentukan sebuah merk, apakah berdasarkan ketertarikan pada merk, kebiasaan pada merk, atau kesesuaian pada harga.
a. Ketertarikan pada Merk
b. Kebiasaan pada Merk
c. Kesesuaian Harga

3. Pilihan Saluran Pembelian

Pelanggan perlu memutuskan mengenai distributor terpilih untuk menggunakan produknya. Setiap pelanggan itu dalam memilih distributor berbeda-beda, misalnya faktor ketersediaan barang, harga, lokasi, kenyamanan belanja, juga keluasan tempat yang merupakan hal yang sangat mempengaruhi pelanggan untuk mencari distributor.
a. Pelayanan yang diberikan Pelayan
b. Persediaan barang

4. Waktu Pembelian

Keputusan konsumen ketika menepatkan waktu pembelian bergantung pada tingkat kebutuhan dan keinginannya, misalnya : ada yang membeli setiap hari, satu minggu sekali, atau bahkan satu bulan sekali. 

a. Kesesuaian dengan kebutuhan
b. Keuntungan yang dirasakan
c. Alasan pembelian

5. Jumlah Pembelian

Konsumen akan mengambil keputusan seberapa banyak produk yang akan ia gunakan dan beli pada waktu tertentu. Perusahaan harus mempersiapkan persediaan barang yang memadai sehingga dapat memenuhi keinginan pembeli yang berbeda-beda.

a. Keputusan jumlah pembelian

b. Keputusan pembelian untuk persediaan

Dalam hal ini konsumen akan membeli sebuah produk untuk persediaan dimana produk tersebut akan digunakan disaat mendatang.

6. Metode Pembayaran

Konsumen dapat mengambil keputusan untuk menggunakan metode pembayaran melalui transaksi secara langsung ataupun secara tidak langsung, misalnya pembayaran tunai atau non tunai yang dapat dilakukan oleh konsumen apabila melakukan pembelian produk.

\section{Kerangka Pemikiran}

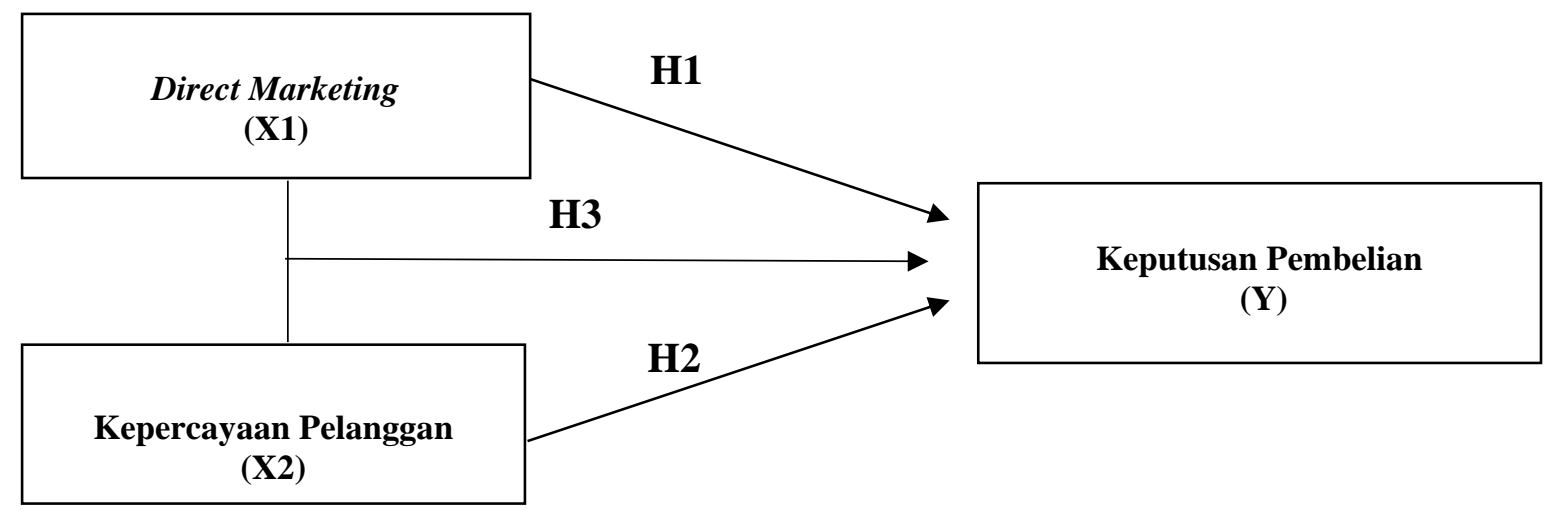

Gambar 1. Kerangka Pemikiran

\section{METODE PENELITIAN}

Metode yang digunakan dalam penelitian ini ialah deskriptif dan verifikatif. Penelitian ini menggunakan kuesioener untuk mendapatkan jawaban tentang penelitian ini dari responden. Populasi diambil dari konsumen yang telah menggunakan jasa umrah di PT. Sanabil Madinah Barakah Bandung yaitu sebanyak 1.135 orang. Sedangkan sampel yang diperoleh dalam peneltian ini dengan perhitungan rumus slovin yaitu sebanyak 92 responden. Dalam penelitian ini menggunakan Teknik nonprobability sampling yaitu Teknik purposive sampling. 
Sebelum dilakukan langkah pengumpulan data, instrument harus diuji dengan menggunakan uji validitas dan uji realibilitas. Sesuai dengan metode penelitian yang digunakan, analisis data dalam penelitian ini menggunakan analisis regresi linier berganda dengan bantuan software SPSS 16.

\section{HASIL DAN PEMBAHASAN}

\section{Validitas Instrumen Penelitian}

Hasil penelitian ini menemukan bahwa paling banyak konsumen jasa umrah pada PT. Sanabil Madinah Barakah Bandung adalah laki-laki yang berusia 21-40 tahun dan telah menempuh pendidikan sarjana dengan pekerjaan sebagai dokter dan lain-lain dengan penghasilan sebesar Rp. 2.600.000-Rp.4.000.000 per bulan. Diketahui bahwa seluruh indikator telah diuji dengan jumlah pernyataan sebanyak 21 digunakan untuk mengukur semua variabel, semua item dinyatakan valid dan nilai yang relevan lebih besar dari 0,3 seperti yang ditunjukan pada tabel 3 berikut :

Tabel 3

\section{Uji Validitas}

\begin{tabular}{|c|c|c|c|}
\hline Variabel & Pertanyaan & r hitung & Ket \\
\hline Diret marketing & Item 1 & 0,579 & Valid \\
& Item 2 & 0,617 & Valid \\
& Item 3 & 0,693 & Valid \\
& Item 4 & 0,504 & Valid \\
\hline Kepercayaan pelanggan & Item 1 & 0,592 & Valid \\
& Item 2 & 0,568 & Valid \\
& Item 3 & 0,594 & Valid \\
& Item 4 & 0,584 & Valid \\
& Item 5 & 0,606 & Valid \\
\hline Keputusan pembelian & Item 1 & 0,629 & Valid \\
& Item 2 & 0,397 & Valid \\
& Item 3 & 0,436 & Valid \\
& Item 4 & 0,394 & Valid \\
& Item 5 & 0,481 & Valid \\
& Item 6 & 0,566 & Valid \\
& Item 7 & 0,362 & Valid \\
& Item 8 & 0,35 & Valid \\
& Item 9 & 0,513 & Valid \\
& Item 10 & 0,614 & Valid \\
& Item 11 & 0,62 & Valid \\
& Item 12 & 0,396 & Valid \\
\hline & diolah) & & \\
& & & \\
& & &
\end{tabular}

Sumber: Output SPSS 16 (data diolah) 
Jika variabel memberikan nilai alpha cronbach > 0,6, maka dikatakan realibel. Pengujian ini menggunakan software IBM SPSS versi 16 dihasilkan semua data realibel, dapat ditunjukan pada Tabel 4 sebagai berikut:

Tabel 4

Uji Realibilitas

\begin{tabular}{|c|c|c|}
\hline Variabel & Alpha Cronbach & Keterangan \\
\hline X1 & 0,722 & Realibel \\
X2 & 0,726 & Realibel \\
Y & 0,709 & Realibel \\
\hline
\end{tabular}

Sumber: Output SPSS 16 (data diolah)

\section{Uji Normalitas}

Uji Normalitas ialah uji statistic yang digunakan untuk mengetahui apakah suatu populasi berdistribusi normal. Uji normalitas pada penelitian ini ditunjukan pada Tabel 5 berikut:

Tabel 5

Uji Normalitas

\begin{tabular}{|c|c|c|c|c|}
\hline & & $\begin{array}{c}\text { Direct } \\
\text { Marketing }\end{array}$ & $\begin{array}{c}\text { Kepercayaan } \\
\text { Pelanggan }\end{array}$ & $\begin{array}{l}\text { Keputusan } \\
\text { Pembelian }\end{array}$ \\
\hline $\mathrm{N}$ & & 92 & 92 & 92 \\
\hline \multirow[t]{2}{*}{ Normal Parameters ${ }^{\mathrm{a}}$} & Mean & 13.92 & 18.15 & 43.90 \\
\hline & Std. Deviation & 2.322 & 2.824 & 5.820 \\
\hline \multirow[t]{3}{*}{ Most Extreme Differences } & Absolute & .176 & .172 & .129 \\
\hline & Positive & .088 & .083 & .071 \\
\hline & Negative & -.176 & -.172 & -.129 \\
\hline Kolmogorov-Smirnov Z & & 1.689 & 1.653 & 1.239 \\
\hline Asymp. Sig. (2-tailed) & & .071 & .086 & .093 \\
\hline
\end{tabular}

a. Test distribution is Normal.

Sumber: Output SPSS 16

Pada Tabel 5 dijelaskan bahwa data pada penelitian ini pada kolom asymp.sig/asymptotic significance ialah setiap variabel seperti direct marketing 0,071, kepercayaan pelanggan 0.086, dan keputusan pembelian 0,93 > 0,05 level of significant $(\alpha)$ sehingga kesimpulannya ialah bahwa setiap data berdistribusi normal. 


\section{Analisis Linier Regresi Berganda}

Regresi linier berganda ialah hubungan secara linier antara dua atau lebih variabel independen (direct marketing dan kepercayaan pelanggan) dengan variabel dependen (keputusan pembelian).

\section{Tabel 6}

\section{Regresi Linier Berganda}

Coefficients $^{\mathrm{a}}$

\begin{tabular}{|c|c|c|c|c|c|c|}
\hline \multirow{2}{*}{\multicolumn{2}{|c|}{ Model }} & \multicolumn{2}{|c|}{$\begin{array}{l}\text { Unstandardized } \\
\text { Coefficients }\end{array}$} & \multirow{2}{*}{$\begin{array}{c}\text { Standardized } \\
\text { Coefficients }\end{array}$} & \multirow[b]{2}{*}{$\mathrm{t}$} & \multirow[b]{2}{*}{ Sig. } \\
\hline & & B & Std. Error & & & \\
\hline 1 & (Constant) & 12.595 & 2.860 & & 4.405 & .000 \\
\hline & Direct marketing & .288 & .181 & .115 & 1.592 & .115 \\
\hline & Kepercayaan pelanggan & 1.504 & .149 & .730 & 10.106 & .000 \\
\hline
\end{tabular}

a. Dependent Variable: Keputusan pembelian Sumber: Output SPSS 16

Dari Tabel 6 didapat persamaan regresi linier bergandasebagai berikut :

$$
\mathrm{Y}=12,595+0,288 \mathrm{X} 1+1,504 \mathrm{X} 2
$$

Pada penelitian ini nilai $\mathrm{X} 1=0,288, \mathrm{X} 2=1,504$ yang berarti positif, artinya jika direct marketing dan kepercayaan meningkat, maka keputusan pembelian akan meningkat.

Tabel 7

\section{Koefisien Determinan}

\begin{tabular}{|c|c|c|c|c|c|c|c|c|c|}
\hline & & & & ode & ummary & & & & \\
\hline \multirow[b]{2}{*}{$\begin{array}{l}\text { Mod } \\
\text { el }\end{array}$} & \multirow[b]{2}{*}{$\mathrm{R}$} & \multirow[b]{2}{*}{$\begin{array}{c}\mathrm{R} \\
\text { Square }\end{array}$} & \multirow[b]{2}{*}{$\begin{array}{l}\text { Adjusted } \\
\text { R Square }\end{array}$} & \multirow{2}{*}{$\begin{array}{l}\text { Std. Error } \\
\text { of the } \\
\text { Estimate }\end{array}$} & \multicolumn{5}{|c|}{ Change Statistics } \\
\hline & & & & & $\begin{array}{c}\text { R Square } \\
\text { Change }\end{array}$ & $\begin{array}{c}\mathrm{F} \\
\text { Change }\end{array}$ & df1 & df 2 & $\begin{array}{c}\text { Sig. F } \\
\text { Change }\end{array}$ \\
\hline 1 & $.784^{\mathrm{a}}$ & .615 & .606 & 3.652 & .615 & 71.050 & 2 & 89 & .000 \\
\hline
\end{tabular}

a. Predictors: (Constant), X2, X1

Sumber: Output SPSS 16

Pada Tabel 7 dijelaskan bahwa koefisien korelasi antara variabel direct marketing, kepercayaan pelanggan dan variabel keputusan pembelian dengan nilai korelasi 0,784. Berikut perhitungan koefisien determinasi (KD) yaitu: $\quad \mathrm{KD} \quad=\mathrm{R}^{2} \mathrm{X} 100 \%$

$$
\begin{aligned}
& =(0,784)^{2} \times 100 \% \\
& =0,615 \times 100 \% \\
& =61,5 \%
\end{aligned}
$$


Menurut perhitungan yang diperoleh hasil koefisien determinasi yaitu sebesar $61,5 \%$. Hal ini menunjukan adanya kontribusi dari direct marketing dan kepercayaan pelanggan terhadap keputusan pembelian sebesar $61,5 \%$ sedangkan sebesar 38,5\% dipengaruhi variabel lain yang tidak terdapat pada penelitian ini.

\section{Pengujian Hipotesis}

Uji T digunakan untuk mencari tahu apakah variabel independen (direct marketing dan kepercayaan pelanggan) secara parsial berimplikasi secara terhadap variabel dependen (keputusan pembelian).

\section{Tabel 8}

Uji T

Coefficients $^{\mathrm{a}}$

\begin{tabular}{|c|c|c|c|c|c|c|}
\hline \multirow{2}{*}{\multicolumn{2}{|c|}{ Model }} & \multicolumn{2}{|c|}{$\begin{array}{c}\text { Unstandardized } \\
\text { Coefficients }\end{array}$} & \multirow{2}{*}{$\begin{array}{c}\text { Standardized } \\
\text { Coefficients } \\
\text { Beta } \\
\end{array}$} & \multirow[b]{2}{*}{$\mathrm{t}$} & \multirow[b]{2}{*}{ Sig. } \\
\hline & & $\mathrm{B}$ & Std. Error & & & \\
\hline 1 & (Constant) & 12.595 & 2.860 & & 4.405 & .000 \\
\hline & Direct marketing & .288 & .181 & .115 & 1.592 & .115 \\
\hline & Kepercayaan pelanggan & 1.504 & .149 & .730 & 10.106 & .000 \\
\hline
\end{tabular}

a. Dependent Variable: Keputusan pembelian

\section{Sumber: Output SPSS 16}

Dari tabel 8 diatas dapat dilihat bahwa secara parsial ada pengaruh antara variabel direct marketing $(1.592>1.29114)$ dan kepercayaan pelanggan $(10,106>1.29114)$ terhadap keputusan pembelian. Karena thitung yang didapat lebih besar dari tabel maka kesimpulannya adalah Ho ditolak dan Ha diterima yang berarti bahwa direct marketing kepercayaan pelanggan berimplikasi terhadap keputusan pembelian.

Uji F digunakan untuk mencari tahu apakah variabel independen (direct marketing dan kepercayaan pelanggan) secara simultan berimplikasi signifikan terhadap variabel dependen (keputusan pembelian). 


\section{Tabel 9}

Uji F

\begin{tabular}{|ll|r|r|r|r|r|}
\hline \multicolumn{7}{|c|}{ ANOVA $^{\mathrm{b}}$} \\
\hline Model & & Sum of Squares & df & Mean Square & \multicolumn{1}{c|}{ F } & \multicolumn{1}{c|}{ Sig. } \\
\hline 1 & Regression & 1895.148 & 2 & 947.574 & 71.050 & $.000^{\mathrm{a}}$ \\
& Residual & 1186.971 & 89 & 13.337 & & \\
& Total & 3082.120 & 91 & & & \\
\hline
\end{tabular}

a. Predictors: (Constant), Kepercayaan pelanggan, Direct marketing

b. Dependent Variable: Keputusan pembelian

\section{Sumber: Output SPSS 16}

Dari tabel 9 nilai Fhitung sebesar 71,050 dan nilai signifikan 0,000 lebih kecil dari 0,05 maka direct marketing dan kepercayaan pelanggan berimplikasi signifikan terhadap keputusan pembelian. Menurut hasil perhitungan yang didapat ialah Fhitung sebesar 71,050 lebih besar dibandingkan Ftabel sebesar 3,099 dan angka signifikan sebesar 0,000 yaitu kurang dari 0,05, artinya H0 ditolak dan Ha diterima. Berarti bahwa direct marketing (X1) dan kepercayaan pelanggan (X2) secara simultan berimplikasi terhadap variabel keputusan pembelian (Y).

\section{Implikasi Direct Marketing Terhadap Keputusan Pembelian}

Melalui uji Kolmogorov Smirnov yang dilihat pada kolom asymp.sig/asymptotic significance, nilai variabel direct marketing adalah 0,071yang berarti bahwa nilai tersebut lebih dari level of significant $(\alpha)$ yaitu 0,05 sehingga dapat disimpulkan bahwa direct marketing berdistribusi normal terhadap keputusan pembelian. Melalui uji regresi linier berganda didapatkan hasil koefisien regresi direct marketing menunjukan tanda positif yaitu sebesar 0,288 , artinya direct marketing berdampak positif terhadap keputusan pembelian, artinya jika persepsi atau evaluasi responden tentang direct marketing meningkat, maka keputusan pembelian pun akan meningkat.

Berdasarkan hasil uji analisis korelasi maka didapat nilai sig. (2-tailed) variabel direct marketing (X1) dengan keputusan pembelian (Y) adalah $0,000<0,05$ maka diantara variabel direct marketing dan keputusan pembelian terdapat korelasi yang signifikan. Hasil penelitian ini menunjukan bahwa hipotesis yang diterima yaitu direct marketing berimplikasi positif terhadap keputusan pembelian, memperkuat penelitian sebelumnya yang dilakukan (Purnama, 2016) menunjukan bahwa pemasaran langsung berimplikasi positif dan signifikan terhadap keputusan pembelian. Selanjutnya dengan uji parsial yaitu uji statistik-T didapat nilai $\mathrm{T}_{\text {hitung }}>$ $\mathrm{T}_{\text {tabel }}$ yaitu $1.592>1.29114$ yang artinya Ha diterima atau secara parsial ada pengaruh variabel 
direct markting terhadap keputusan pembelian. Peneliti mengaitkan penelitian ini dengan ungkapan para ahli yaitu menurut (Williams \& Mullin, 2009), direct marketing memiliki banyak keunggulan, yaitu tentu saja dapat memberikan keuntungan karena adanya target pelanggan yang jelas.

\section{Implikasi Kepercayaan Pelanggan Terhadap Keputusan Pembelian}

Melalui uji Kolmogorov Smirnov dapat dilihat pada kolom asymp.sig/asymptotic significance, nilai variabel kepercayaan pelanggan adalah 0,086 yang berarti bahwa nilai tersebut lebih dari level of significant $(\alpha)$ yaitu 0,05 sehingga dapat disimpulkan bahwa kepercayan pelanggan berdistribusi normal terhadap keputusan pembelian. Melalui uji regresi linier berganda didapatkan hasil koefisien regresi kepercayaan pelanggan menunjukan tanda positif yaitu sebesar 1,504 artinya kepercayaan pelanggan berimplikasi positif terhadap keputusan pembelian, artinya jika persepsi atau evaluasi responden terhadap kepercayaan pelanggan meningkat, maka keputusan pembelian pun meningkat. Berdasarkan hasil uji analisis korelasi, maka didapat nilai sig. (2-tailed) variabel kepercayaan pelanggan (X2) dengan keputusan pembelian (Y) adalah sebesar $0,000<0,05$ dapat diambil kesimpulan bahwa antara variabel kepercayaan pelanggan dan keputusan pembelian terdapat korelasi yang signifikan. Selanjutnya dengan menggunakan uji parsial yaitu uji statistik-T didapat nilai $\mathrm{T}_{\text {hitung }}>\mathrm{T}_{\text {tabel }}$ yaitu 10,106 > 1.29114 yang artinya Ha diterima atau secara parsial ada implikasi variabel kepercayan pelanggan terhadap keputusan pembelian. Penelitian ini dikaikan dengan (Siow, 2013) yang menunjukan bahwa kepercayaan pelanggan secara parsial akan mempengaruhi keputusan pembelian.

\section{Implikasi Direct Marketing Dan Kepercayaan Pelanggan Terhadap Keputusan Pembelian}

Pengujian melalui Uji F untuk mencari tahu apakah variabel independen (direct marketing dan kepercayaan pelanggan) secara simultan berimplikasi secara signifikan terhadap variabel dependen (keputusan pembelian) mendapatkan hasil dengan nilai Fhitung sebesar 71,050 dengan tingkat signifikan 0,000 lebih kecil dari 0,05 maka direct marketing dan kepercayaan pelanggan berimplikasi signifikan terhadap keputusan pembelian. Berdasarkan pada hasil perhitungan Fhitung sebesar 71,050 lebih besar dari Ftabel sebesar 3,099 dan angka signifikan sebesar 0,000 yaitu $<0,05$. Hal ini berarti H0 ditolak dan Ha diterima. Dengan demikian, berarti direct marketing (X1) dan kepercayaan pelanggan (X2) secara bersama-sama 
berimplikasi terhadap variabel keputusan pembelian (Y). edangkan melalui uji koefisien determinasi dengan nilai Rsquare 0,615 dengan nilai persentase $61,5 \%$ yang berarti bahwa hal ini menunjukkan bahwa prosentase sumbangan pengaruh variabel independen (direct marketing dan kepercayaan pelanggan) mampu menjelaskan sebesar 61,5\% variasi variabel dependen (keputusan pembelian). Sedangkan sisanya sebesar 38,5\% (100\%-61,5\%) dipengaruhi atau dijelaskan oleh variabel yang tidak dimasukkan dalam penelitian ini misalnya seperti harga dan kualitas pelayanan.

Hasil penelitian ini serupa dengan penelitian yang dilakukan oleh (Yusuf, 2013) yang mengemukakan bahwa direct marketing bisa mempengaruhi dalam pengambilan keputusan pembelian yang akan di lakukan. Semakin besar atau gencarnya teknik direct marketing yang dilakukan sebuah perusahaan maka akan semakin besar pula dalam mempengaruhi keputusan pembelian seorang konsumen. Juga sama dengan penelitian dari (Tajudin dan mulazid, 2017) yang menyatakan hal yang sama dalam penelitian yang dilakukan bahwa kepercayaan berpengaruh signifikan terhadap keputusan pembelian.

Berdasarkan hasil penelitian ini, temuan lain dari penelitian ini adalah variabel berimplikasi signifikan terhadap keputusan pembelian adalah kepercayaan pelanggan terdiri dari 3 indikator yaitu kebaikan hati, integritas dan kemampuan dimana terdapat indikator yang sangat mendukung untuk meningkatkan kepercayaan pelanggan. Semakin baik pengendalian perusahaan terhadap pelayanan karyawan, fasilitas yang diberikan, dan jaminan keamanan terhadap pelanggan, maka akan semakin baik pula kondisi kepercayaan pelanggan yang ada pada perusahaan yang pada akhirnya dapat mendukung perusahaan dalam upaya meningkatkan keputusan pembelian.

\section{PENUTUP}

Penelitian ini bertujuan untuk mengkaji implikasi direct marketing dan kepercayaan pelanggan terhadap keputusan pembelian tiket umrah pada PT. Sanabil Madinah Barakah Bandung. Setelah dilakukan pengujian terhadap 92 responden, pengujian menghasilkan bahwa direct marketing dan kepercayaan pelanggan berimplikasi positif terhadap keputusan pembelian. Apabila direct marketing dan kepercayaan pelanggan dilakukan dengan baik oleh perusahaan maka akan menghasilkan keputusan pembelian yang maksimal. Saran yang bermanfaat bagi perusahaan yaitu perusahaan harus meningkatkan promosi melalui direct marketing juga meningkatkan kepercayaan pelanggan pada PT. Sanabil Madinah Barakah. Saran bagi berharap lebih banyak peneliti untuk menambah atau menemukan variabel baru yang terkait dengan keputusan pembelian. Sehingga dapat memberikan informasi baru tentang 
variabel lain (harga, kualitas produk, kualitas pelayanan, advertising) yang dapat berimplikasi terhadap keputusan pembelian selain direct marketing dan kercayaan pelanggan yang digunakan peneliti dalam tugas akhir. 


\section{REFERENSI}

Armstrong, G., Adam, S., Denize, S., \& Kotler, P. (2014). Principles of marketing. Australia: Pearson.

Bennett, A. G. (2010). The Big Book of Marketing. Tata McGraw-Hill Education.

Gwartney, J., Lawson, R., \& Norton, S. (2008). Economic Freedom of The World: 2008 Annual Report. The Fraser Institute.

James, G.B. (2003). Secrets of Customer Relationship Management. Terjemahan Andreas Winardi. Yogyakarta: Andi.

Kotler, P, Keller, K. L., MarkKotler, P., \& Keller, K. L. (2016). Marketing Management. Global Edition (Vol. 15E).

Kotler, P. (n.d.). Gary amstrong. (2008). Prinsip-Prinsip Pemasaran. Jilid I. Edisi Kesembilan. Jakarta: Erlangga.

Kotler, Philip, \& Armstrong, G. (2012). Alih Bahasa: Bob Sabran, Prinsip-Prinsip Pemasaran, edisi 13 jilid 1. Jakarta: Penebit Erlanga.

Kotler, Philip, \& Keller, K. L. (2007). A framework for marketing management.

Mayer, R. C., Davis, J. H., \& Schoorman, F. D. (1995). An Integrative Model of Organizational Trust, Academy of Management Review, 20 (3): 709-734.

Mowen, J. C., \& Minor, M. S. (2003). Comportamento do consumidor.

Purnama, R. (2016). Pengaruh Direct Marketing Terhadap Keputusan Pembelian Di. 1: 973982.

Rodriguez, M., Dixon, A. L., \& Peltier, J. W. (2014). A Review of The Interactive Marketing Literature in The Context of Personal Selling and Sales Management, Journal of Research in Interactive Marketing.

Saladin, D. (2003). Manajemen Pemasaran, Analisis, Perencanaan, Pelaksanaan dan Pengendalian. Bandung: Linda Karya.

Schiffman, L. G., \& Kanuk, L. L. (2004). Nákupní chování. Computer Press.

Siow, N. (2013). Kualitas Layanan Dan Kepercayaan Pelanggan Pengaruhnya terhadap Keputusan Pembelian Sepeda Motor Suzuki Satria Fu150 Di Kota Manado, Jurnal Riset Ekonomi, Manajemen, Bisnis Dan Akuntansi, 1 (3): 1069-1078.

Suparwo, A., Riana, D., \& Sari, R. D. (2017). Pelaksanaan Personal Selling Dalam Pengaruhnya Terhadap Keputusan Pembelian Polis Asuransi, Ecodemica, 1(2): 224-251. https://doi.org/10.31311/jeco.v1i2.2258.

Swastha, B.D.H. (2007). Azas-Azas Marketing. Yogyakarta: Liberty.

Tajudin, M. H., \& Mulazid, A. S. (2017). Pengaruh Promosi, Kepercayaan dan Kesadaran 
Merek Terhadap Keputusan Nasabah Menggunakan Produk Tabungan Haji (Mabrur) Bank Syariah Mandiri Kcp. Sawangan Kota Depok, ISLAMICONOMIC: Jurnal Ekonomi Islam, 8(1): 19-46. https://doi.org/10.32678/ijei.v8i1.64.

Tjiptono, F. (2008). Strategi Pemasaran. Edisi 3. Yogyakarta: Andi.

Wahyuni, N.W.S., and Darma, G.S. (2019). Mobile Advertising, Product Social Value dan Purchase Intention pada Instagram, Jurnal Manajemen Bisnis, 16 (4): 87-101.

Williams, A., \& Mullin, R. (2009). The Handbook of Field Marketing: A Complete Guide to Understanding and Outsourcing Face-to-Face Direct Marketing. Kogan Page Publishers.

Yusuf, R. B. (2013). Pengaruh Direct Marketing Dan Personal Selling Terhadap Keputusan Pembelian Keripik Singkong "Singkongku" di Desa Danasari Kecamatan Bojong Kabupaten Tegal, Journal of Chemical Information and Modeling, 53(9): 1689-1699. https://doi.org/10.1017/CBO9781107415324.004. 